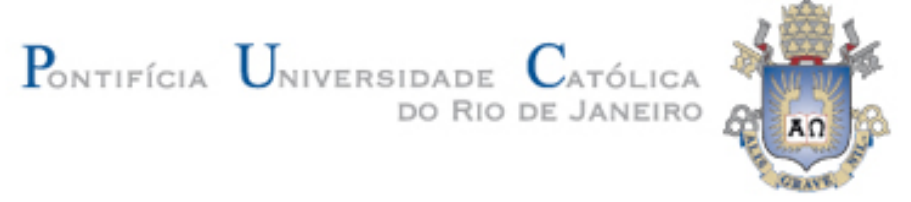

Moisés Ribeiro da Silva

Visualização de Informação e
Retórica Visual no Jornalismo Digital

Dissertação de Mestrado

Dissertação apresentada ao Programa de Pós-Graduação em Design da PUC-Rio como requisito parcial para obtenção do título de Mestre em Design.

Orientadora: Prof. Rejane Spitz

Rio de Janeiro

Março de 2012 
Moisés Ribeiro da Silva

\section{Visualização de Informação e Retórica Visual no Jornalismo Digital.}

Dissertação apresentada ao Programa de PósGraduação em Design da PUC-Rio como requisito parcial para obtenção do grau de Mestre em Design. Aprovada pela Comissão Examinadora abaixo assinada.

Profa. Rejane Spitz Orientador

Departamento de Artes \& Design - PUC-Rio

Prof. Nilton Gonçalves Gamba Junior Departamento de Artes \& Design - PUC-Rio

Profa. Luiza Novaes

Departamento de Artes \& Design - PUC-Rio

Profa. Denise Berruezo Portinari Coordenadora Setorial do Centro de Teologia e Ciências Humanas - PUC-Rio 
Todos os direitos reservados. É proibida a reprodução total ou parcial do trabalho sem autorização da universidade, do autor e da orientadora.

\section{Moisés Ribeiro da Silva}

Graduou-se em Design Gráfico no Centro Universitário Ritter dos Reis (UniRitter) em 2007. Em 1998, concluiu o ensino técnico de Artes Gráficas no SENAI Henrique D’Ávila Bertaso. Atuou na área de produção gráfica e em 2005 passou a trabalhar com mídias digitais, com foco em design de experiência e arquitetura de informação, participando desde então de diversos cursos e seminários na área. Atualmente, é coordenador de produtos na área de jornalismo da Globo.com.

Ficha Catalográfica

Silva, Moisés Ribeiro da

Visualização de informação e retórica visual no jornalismo digital / Moisés Ribeiro da Silva ; orientadora: Rejane Spitz. - 2012.

140 f. : il.(color.) ; $30 \mathrm{~cm}$

Dissertação (mestrado) - Pontifícia Universidade Católica do Rio de Janeiro, Departamento de Artes e Design, 2012.

Inclui bibliografia

1. Artes e design - Teses. 2. Visualização de informação. 3. Visualização de dados. 4. Jornalismo digital. 5. Retórica visual. 6. Design de informação. 7. experiência do usuário. 8. Novas mídias. I. Spitz, Rejane. II. Pontifícia Universidade Católica do Rio de Janeiro. Departamento de Artes e Design. III. Título. 


\section{Agradecimentos}

À minha orientadora, Rejane Spitz, que com apontamentos primorosos e sua grande visão a respeito do design e das novas mídias me ajudou a conduzir essa dissertação.

À minha esposa, Andrea, que com amor, compreensão e paciência foi uma incentivadora implacável do meu empenho, especialmente nos momentos mais críticos do percurso dessa pesquisa.

À minha família, que mesmo à distância jamais deixou de me apoiar. Aos meus pais, Aliardo e Teresinha, que foram fonte de exemplo para minha caminhada e perseverança.

Aos colegas da Globo.com pelo incentivo e amizade.

À PUC-Rio, pelos auxílios concedidos, sem os quais este trabalho não poderia ter sido realizado.

Aos professores que participaram da Comissão Examinadora. 


\section{Resumo}

Silva, Moisés Ribeiro da; Spitz, Rejane. Visualização de Informação e

Retórica Visual no Jornalismo Digital. Rio de Janeiro, 2012. 140p. Dissertação de Mestrado - Departamento de Artes \& Design, Pontifícia Universidade Católica do Rio de Janeiro.

Esta pesquisa analisa o campo do design especialmente no que tange à produção de visualização de informação para meios digitais no âmbito do jornalismo, com o olhar voltado para a retórica visual dessas imagens. Relacionada com o advento das novas mídias - que trouxe a viabilidade de representações visuais a partir de bases de dados dinâmicas - a pesquisa visa contribuir para uma discussão ainda incipiente em nível global (e especialmente nacional) dado o cenário tecnológico contemporâneo, caracterizado pela multimidialidade e pela crescente popularidade de novos dispositivos computacionais, interativos e portáteis. Para tal, empreende uma reflexão teórica que passa pelo estabelecimento da sociedade de informação no último século; apresenta a transição das velhas para as novas mídias, bem como seu impacto no jornalismo e, por consequência, na visualização de informação produzida para esses meios; e investiga ainda, o campo da imagem e da compreensão de informação através da retórica visual. A partir dessa moldura teórica, esta dissertação apresenta uma proposta de organização do uso da retórica visual de forma consciente por designers, através de uma taxonomia baseada em estudos anteriores. E finalmente, com base nessa proposta, analisa determinados casos de uso, classificando visualizações de informação produzidas por alguns veículos de mídia, do Brasil e do exterior.

\section{Palavras-chave}

Visualização de informação; visualização de dados; jornalismo digital; retórica visual; design de informação; experiência do usuário; novas mídias. 


\section{Abstract}

Silva, Moisés Ribeiro da; Spitz, Rejane (Advisor). Information visualization and visual rhetoric on digital journalism. Rio de Janeiro, 2012. 140p. MSc. Dissertation - Departamento de Artes \& Design, Pontifícia Universidade Católica do Rio de Janeiro.

This research investigates the Design domain especially on information visualization (InfoVis) production to digital media through journalism, focusing on images' visual rhetoric. Concerned with the advent of new media - that brought the viability of dynamic data onto visual representations - this study wants to contribute to an initial global debate (and particularly in Brazil) in view of the contemporary technologic scenario characterized by multimediality and growing popularity of new interactive and portable computational devices. For that, it does a theoretical study on information society; it presents the transition between old and new media, as well as the impact on journalism and, in consequence, on information visualization production by new media; and also, investigates the image field and information comprehension through visual rhetoric. Within this theoretical frame, the dissertation proposes a conscious and organized use of visual rhetoric for designers, with a taxonomy based on earlier researches. Finally, based on this proposal, this study analyses some usage cases, classifying information visualization produced by some brazilian and international media companies.

\section{Keywords}

Information visualization (InfoVis); data visualization; digital journalism; visual rhetoric; information design; user experience; new media. 


\section{Sumário}

1. Introdução 11

2. Do design de informação 18

2.1. A sociedade de informação 22

2.2. A informação nas novas mídias 26

2.3. A questão ética do projeto de informação 33

3. O jornalismo na era da internet 36

3.1. A transposição da mídia tradicional para as novas mídias 37

3.2. A velha prática em um novo contexto 40

3.3. Sobre a visualização de informação no jornalismo 43

4. A cultura imagética $\quad 52$

4.1. As mensagens da imagem 53

4.2. A retórica visual do design $\quad 58$

4.3. Visualização de informação: a evolução da representação gráfica 64

4.4. Visualizações de caráter exploratório ou retórico? 73

5. Estudos de Caso $\quad 75$

5.1. As camadas editoriais $\quad 75$

5.1.1. A camada de dados $\quad 76$

5.1.2. A camada de representação visual $\quad 77$

5.1.3. A camada de anotação $\quad 81$

$\begin{array}{ll}\text { 5.1.4. A camada de interatividade } & 81\end{array}$

5.2. Escolha dos veículos de comunicação 83

5.3. Escolha dos casos $\quad 84$

5.4. Análise dos casos $\quad 85$

5.5 Considerações sobre os estudos de caso 126

6. Considerações Finais 134

$\begin{array}{ll}\text { 7. Referências Bibliográficas } & 138\end{array}$ 


\section{Lista de Figuras}

Fig. 01 - Continuum da Compreensão

Fig. 02 - Dos fundamentos teóricos à aplicação prática: disciplinas

relacionadas com a visualização de informação/infografia jornalística

Fig. 03 - Exemplo de diagrama gráfico concebido por William Playfair

Fig. 04 - Wohndichte in Großstädten (densidade residencial em grandes cidades), projeto de Otto Neurath em 1930

Fig. 05 - Interface visual do projeto Sync/Lost

Fig. 06 - Tag Cloud (nuvem de tags) que apresenta uma visualização da população mundial em diversos países, com dados de 2007

Fig. 07 - Organograma: Os dois grandes grupos de infográficos

Fig. 08 - Exemplo de infográfico enciclopédico publicado pelo jornal

Estadão mostrando detalhes da construção do monumento ao Cristo

Redentor no Rio de Janeiro

Fig. 09 - Exemplo de infográfico jornalístico publicado pelo The New York Times cobrindo o detalhamento das despesas da proposta de orçamento do governo americano para 2012

Fig. 10 - Anúncio Panzani, objeto de análise de Roland Barthes

Fig. 11 - Exemplo de visualização de informação através de mapas de dados, produzido para o aplicativo de iPad "State of the Union" da GE por Fathom Information Design , que mapeia informações sobre a área da saúde dos Estados Unidos

Fig. 12 - Exemplo de visualização de informação "A Evolução da Internet", através de linha do tempo, produzida pela equipe de desenvolvimento do navegador Google Chrome

Fig. 13 - Exemplo de visualização de dados e representação tempo-espacial através de linha do tempo produzida pelo jornal inglês The Guardian para a cobertura dos protestos no Oriente Médio a partir de 2010

Fig. 14 - Exemplo de visualização de informação relacional, concebido por Pitch Interactive, cruzando dados do governo americano e do serviço de dados do jornal NYTimes 
Fig. 15 - Visualização exploratória produzida pelo grupo de pesquisa

Software Studies utilizando 4535 imagens de capas da revista

Time Magazine, compreendendo o período entre 1923 e 2009

Fig. 16 - Modelo gráfico para análise de retórica visual

Fig. 17 - Figuras resultantes a partir do modelo de operação de Adjunção retórica

Fig. 18 - Figuras resultantes a partir do modelo de operação de

Supressão retórica

Fig. 19 - Figuras resultantes a partir do modelo de operação de

Substituição retórica

80

Fig. 20 - Figuras resultantes a partir do modelo de operação de

Troca retórica

80

Fig. 21 - Caso 01: "Naming Names" por The New York Times 86

Fig. 22 - Caso 02: "A Map of Olympic Medals" por The New York Times 88

Fig. 23 - Caso 03: "How political shifts have altered the map of

Europe" por The Guardian

90

Fig. 24 - Caso 04: "Guantánamo files: all 779 detainees" por The Guardian

Fig. 25 - Caso 05: "A nova Assembleia Legislativa de São Paulo"

por O Estado de S.Paulo

Fig. 26 - Caso 06: "Os reis dos pontos corridos no Campeonato

Brasileiro" por O Estado de S.Paulo 96

Fig. 27 - Caso 07: "Mapping America” por The New York Times 98

Fig. 28 - Caso 08: "Anders Breivik's manifesto mapped" por The Guardian 100

Fig. 29 - Caso 09: "UK riots: every verified incident" por The Guardian 102

Fig. 30 - Caso 10: "A desigualdade de desempenho das escolas

no Enem 2010" por O Estado de S.Paulo 104

Fig. 31 - Caso 11: "Murder: New York City" por The New York Times 106

Fig. 32 - Caso 12: "Veja como funciona a bateria da Grande Rio" por iG 108

Fig. 33 - Caso 13: "Top World Cup Players on Facebook" por

The New York Times 110

Fig. 34 - Caso 14: "Doador de Órgão fica mais velho no Brasil” por iG 112

Fig. 35 - Caso 15: "Arab Spring: an interactive timeline of Middle

East protests" por The Guardian

Fig. 36 - Caso 16: "Taupuiassauro, o novo dinossauro do Brasil"

por O Estado de S.Paulo

Fig. 37 - Caso 17: "Morumbi, um palco para craques" por

O Estado de S.Paulo 
Fig. 38 - Caso 18: "A Apple sob Steve Jobs” por iG 120

Fig. 39 - Caso 19: "Doador de Órgão fica mais velho no Brasil" por iG 122

Fig. 40 - Caso 20: "Mobilidade no Ensino Superior em 2011" por iG 124

Fig. 41 - Visualização de informação criada por Jer Thorp utilizando a API Open Platform do The Guardian. A imagem mostra as menções

a Tony Blair e Gordon Brown nos artigos do jornal entre 1999 e 2008, devendo ser lido em sentido horário

Fig. 42 - O designer e desenvolvedor de software Mike Matas apresenta em uma conferência TED o livro interativo "Our Choice" (2009) e interage com uma visualização de informação através do sopro do iPad 